\title{
ANALYSIS OF RISK ASPECTS OF GOLD MORTGAGE PRODUCTS
}

\author{
Scholastika ${ }^{1}$, Kamaluddin $^{2}$, Hamni Fadilah ${ }^{3}$, Rahmat Annam ${ }^{4}$ \\ ${ }^{1}$ IAIN Padangsidimpuan (Perbankan Syariah, FEBI, IAIN Padangsidimpuan) \\ ${ }^{2}$ IAIN Padangsidimpuan (Perbankan Syariah, FEBI, IAIN Padangsidimpuan) \\ ${ }^{3}$ IAIN Padangsidimpuan (Perbankan Syariah, FEBI, IAIN Padangsidimpuan) \\ ${ }^{4}$ IAIN Padangsidimpuan (Perbankan Syariah, FEBI, IAIN Padangsidimpuan) \\ scholastika@gmail.com ${ }^{1}$, kamaluddin@iain-padangsidimpuan.ac.id ${ }^{2}$, hamnifadilah@iain- \\ padangsidimpuan.ac.id $^{3}, \underline{\text { rahmatannam@iain-padangsidimpuan.ac.id }}^{4}$
}

\begin{abstract}
ABSTRAK
Penelitian ini dilatarbelakangi oleh analisis aspek risiko produk gadai emas pada PT. Pegadaian (Persero) Unit Pelayanan Syari'ah Sibuhuan. Jenis emas dan harga emas yang bervariasi dipasar menimbulkan terjadinya risiko. Penurunan harga emas akan berakibatkan kerugian pada saat lelang bagi PT. Pegadaian (Persero) Unit Pelayanan Syari'ah Sibuhuan. Pegadaian lebih cermat dalam mengikuti perkembangan harga emas di pasaran dan juga jenis-jenis emas yang beredar, harus lebih cermat dan teliti dalam menaksir barang. Tujuan dari penelitian ini untuk mengetahui risiko produk gadai emas. Teori yang dipaparkan dalam penelitian ini berkaitan dengan pegadaian syari'ah, teori tentang risiko gadai emas, teori tentang yang berkaitan beberapa ketidakpastian ekonomi (economic uncertainty), ketidak pastian alam (uncertainty of nature), ketidakpastian manusia (human uncertainty). Penelitian ini merupakan penelitian kualitatif dengan metode deskriptif sumber data yang digunakan adalah data primer dan data sekunder. Sedangkan teknik pengumpulan data penelitian ini adalah wawancara, observasi dan dokumentasi. Hasil penelitian Analisis Aspek Risiko Produk Gadai Emas yang terjadi pada PT. Pegadaian (Persero) Unit Pelayanan Syari'ah Sibuhuan adalah Risiko pasar yaitu penurunan harga emas yang mengakibatkan kerugian pada saat terjadinya lelang, risiko kredit yaitu risiko yang diakibatkan ketidak mampuan nasabah dalam melunasi kewajibannya, risiko operasional yaitu risiko yang timbul oleh ketidakcukupan dalam proses manajemen seperti masuknya emas palsu, lalai dalam melakukan penaksiran barang jaminan, risiko hukum yaitu terjadinya kejahatan baik pencurian maupun kecurangan pegawai, risiko reputasi yaitu yang disebabkan keluhan nasabah terhadap produk atau layanan yang ada di PT. Pegadaian (Persero) Unit Pelayanan Syari'ah Sibuhuan dan risiko bencana alam (force majeur) yaitu risiko yang menimbulkan kerugian dengan terjadinya bencana. Langkah-langkah yang dilakukan PT. Pegadaian (Persero) Unit Pelayanan Syari'ah Sibuhuan untuk meminimalisasikan risiko terhadap produk gadai emas dengan melakukan pemantauan, pembinaan dan pengawasan. Dilaksanakan pendidikan untuk para penaksir untuk mengupdate pengetahuan dan merefresh pengetahuan penaksir-penaksir yang ada di pegadaian.
\end{abstract}

Kata Kunci: Gadai Emas, Pegadaian, Risiko

\section{ABSTRACT}

This research is motivated by the analysis of the risk aspects of gold pawn products at PT. Pegadaian (Persero) Sibuhuan Syari'ah Service Unit. The types of gold and the varying price of gold in the market pose risks. The decline in gold prices will result in losses during the auction for PT. Pegadaian (Persero) Sibuhuan Syari'ah Service Unit. Pegadaian is more careful in following the price developments in the market, as well as the types of gold that supervises, must be more careful and thorough in assessing goods. What are the risks that occur in gold pawn products at PT. Pegadaian (Persero) Sibuhuan Sharia Service Unit. How are the steps to minimize the risk of products that are pawning gold. The purpose of this research is to see the risk of gold pawn products. The theory presented in this study is related to shari'ah pawnshops, the theory of gold pawn risk, the theory of economic uncertainty, natural uncertainty, human uncertainty. This research is a qualitative research with descriptive method. The data source used is primary data and secondary data. While the technique, the data of this research are interviews, observation and documentation. The results of the research on the Analysis of the Risk Aspects of Gold Pawn Products that occurred at PT. Pegadaian (Persero) Syari'ah Sibuhuan Service Unit is a market risk, namely a decrease in the price of gold which results in losses at the time of the auction, credit risk, namely the risk caused by the inability of the 
POINT Vol. 2, No. 1, Jul 2021 customer to pay off its obligations, operational risk, namely the risk arising from inadequacy in the management process. such as the entry of counterfeit gold, negligence in appraising collateral, legal risk of criminal acts either robbery or employee fraud, reputation risk, namely due to customer complaints against products or services at PT. Pegadaian (Persero) Syari'ah Sibuhuan Service Unit and natural disasters (force majeure), namely risks that cause losses with catastrophic disasters. The steps taken by PT. Pegadaian (Persero) Syari'ah Sibuhuan Service Unit to minimize the risk of gold pawn product risk by conducting supervision, guidance and supervision. Education is carried out for appraisers to update knowledge and refresh the existing estimators in the pawnshop.

Keywords: Gold Pawn, Pawnshop, Risk

\section{A. PENDAHULUAN}

Sebagaian umat Islam di Indonesia telah mampu mensyukuri atas nikmat Allah mulai memanfaatkan peluang dan mendukung berdirinya bank syari'ah Asuransi syari'ah dan reksadana syari'ah, dalam bentuk pemegang saham, menjadi penabung dan nasabah, bisa juga pemegang polis, investor dan sebagainya. Dan banyak pula yang secara krestif mengembangkan ide untuk berdirinya lembaga keuangan syari'ah bukan bank lainnya seperti modal ventura, lesing dan pegadaian.(Adrian Sutedi: 2011, 12).

Perkembangan produk-produk berbasis syari'ah kianzmarak di Indonesia \& tidak terkecuali pegadaian. Perum pegadaian mengeluarkan produk berbasis syari'ah yang disebut dengan pegadaian syari'ah. Pada dasarnya produk-produk berbasis syari'ah memiliki karakteristik, seperti tidak memungutbunga dalam berbagai bentuk karena riba,"menetapkan sebagai alat tukar, bukan sebagai komoditas yang perdagangkan dan melakukan bisnis untuk memperoleh imbalan atas jasa dan bagi hasil. (Khaerul Umam: 2013, 355)
Islam membenarkan madanya praktikf pegadaian yang dilakukan dengan tujuan tidak merugikan orang lain. Pegadaian dibolehkan dengan syarat rukun*bebas dari unsur"yang dilarang dangmerusak perjanjian gadai. Pegadaian berlaku di masyarakat, masih terdapat satu di antara banyakpunsur yang dilarang oleh syara. Yaitu dalam upaya meraih keuntungan, pegadaian? memungut sewa modal lebih lazim disebut bunga. Lahirnya pegadaian syari'ah diharapkan dapat menjawab kebutuhan masyarakat beragam Islam diterbitkannya fatwa MUI tentang pengharaman bunga. Meski didirikan landasan syari'ah Islam, pegadaian syari'ah menjadi alternatif utama bagi masyarakat yang ingin memperoleh danansegar secara aman, cepat serta memberi berkah bagi keseluruhan umat. (Adrian Sutedi: 2011, 13)

Menurut-Zainuddin dan Jamhari, gadai iadalah menyerahkan benda berharga dari seorang kepadaa orang lainisebagai penguat atau tanggungan dalam utang piutang. Benda akan dikembalikan setelahuutangnya terbayar, jika waktu pembayaran telah ditentukan dan utang belum dibayarrmaka barang"digunakan sebagai ganti yaitu-dengan cara dijual*sebagai 
bayaran dannjika ada kelebihan

dikembalikan*kepada oranggyang"berutang.

Hasil wawancara dengan Bapak Sayuti Nur dalam aspek perusahaan risikonya, Jika menggadaikan emas harga emas fluktuatif, kejadian pada tahun 2013 PT. Pegadaian (Persero) Unit Pelayanan Syari'ah Sibuhuan tidak cepat melihat harga emas dunia yang sedang turun terus menurun, jadinya harga emas dipasar dibeli selisi harga disitu disebut kerugian, apabila perusahan tidak cepat melihat turunnya harga emas maka perusahaan akan rugi.(Sayuti Nur: 2020)

Seperti diketahui emas mempunyai aspek menyentuh kebutuhan manusia. Emas juga mempunyai manfaat Eemosional dinikmati keindahannya. Sudah Mada kesepakatan budaya atas segala global emas adalah logam mulai nilai etetis sangat tinggi. Nilai keindahannya berpadu pada harganya yang menarik sehingga menjadilah emas sarana mengeskspresi diri, emas telah menjadi symbol status sub-kultur di Indonesia. Emas juga komoditas yang sangat berharga dan likuid, ketika kita memiliki emas maka memiliki harta yang sewaktu-waktu bisa dicarkan, ditukarkann dengan uang waktu cepat mudah diperjual belikan sifatnya universal dapat dihargai dimanapun.

Menurut A. Abas Salim, risiko yaitu ketidaktentuan yang mungkin menimbulkan kerugian. Dalam dunia bisnis ketidakpastian beserta risikonya merupakan sesuatunyang tidak dapat diabaikan begitu saja, malahan harus diperhatikan secara teliti, Risiko tersebut kebakaran, kerusakan, pencurian, penipuan, kecurangan, dan sebagainya dapat menimbulkan kerugian yang tidak kecil. Manajemen risiko bagi pegadaian dipastikan mengarah ke satu titik yakni risiko operasional, risiko kredit dalam pengertian pegadaian selaku pemberian kredit dan nasabah melakukan wanprestasi sehingga kredit yang disalurkan pegadaian terbayar nasabah.(Ahmad Nizar: 2014, 245)

Hasil pengamatan peneliti menunjukkan bahwa semua produk yang di Unit Pegadaian Syari'ah Sibuhuan memiliki risiko masing-masing, hanya risiko yang ada pada gadai syari'ah rahn lebih tinggi dibandingkan dengannrisiko yang ada pada produk lainnya. Jika dibuat dalam bentuk persentase besarnya tingkat risiko pada gadai syari'ah mencapai 80 persen sedangkan risiko untuk produk lainnya hanya mencapai 15 persen. Hasil pengamatan peneliti juga menunjukkan bahwa tingkat risiko yang terjadi terhadap produk gadai emas sangat tinggi.

Setiap usaha bisnis atau pendirian perusahaan mendapatkan hasil dari kegiatan maka harus menghadapi risiko, sebaliknya tidaak mengambil risiko sama sekali adalah salah karena tisaak ada peluang sama sekali untuk memperoleh hasil. Risiko harus dihadapi setiap aktifitas sehingga memberikan peluang, memperoleh hasil yang diharapkan.

Namun risiko yang ada harus dikelolah dengan baik tidak terkecuali pada pegadaian 
syari'ah merupakan sebuah lembagan keuangan umat yang memiliki proses yang baik, juga memiliki system manajemen pengawasan risiko segala tindakan yang mampu mencegah bahkan menghilangkan risiko, kerugian financial dari kegiatan perusahaan. Sudah sepantasnya organisasi atau perusahaan menyadari bahwa pengolahan risiko merupakan hal penting bagi organisasi atau perusahaan menyadari bahwa pengolahan risiko merupakan hal yang penting bagi organisasi atau perusahaan sehingga perlu untuk memiliki yang namanya suatu sistem manajerial yang mampu meminimalisir bahkan menghilangkan segala risiko yang sedang dihadapi dalam kegiatan perusahaan, dan organisasi memiliki sebuah sistem manajemen dan pengawasan risiko.

Berdasarkan uraian di atas maka peneliti tertarik mengangkat judul ini dengan judul "Analisis Aspek Risiko Produk Gadai Emas".

\section{B. METODE}

Penelitian dilakukan di PT. Pegadaian (Persero) Unit Pelayanan Syari'ah Sibuhuan dengan menggunakan metode penelitian kualitaitif deskriftif, subjek penelitian karyawan PT. Pegadaian (Persero) Unit Pelayanan Syari'ah Sibuhuan yang bersangkutan dengan penelitian ini dengan menggunakan sumber data primer dan data sekunder, metode pengumpulan data yaitu: observasi, wawancara terstuktur dengan menggunakan pedoman wawancara, observasi dan dokumentasi. Metode pengecekan
POINT Vol. 2, No. 1, Jul 2021 keabsahan data yaitu triangulasi, triangulasi sumber, dan menggunakan bahan referensi metode analisis data yaitu rudukasi data, penyajian data dan penarikan kesimpulan.

\section{HASIL DAN PEMBAHASAN}

Prosedur dan Mekanisme Produk Gadai Emas Pada PT. Pegadaian (Persero) Unit Pelayanan Syari'ah Sibuhuan

Mekanisme operasional gadai syari'ah sangat penting untuk diperhatikan karena jangan sampai operasional gadai syari'ah tidak efektif dan efesien. Mekanisme operasional gadai syari'ah haruslah tidak menyulitkan calon nasabah yang akan meminjam uang atau akad melakukan akad utang piutang. Akad yang dijalankan termasuk jasa dan produk yang dijual juga harus selalu berlandaskan syari'ah Islam (al-Quran, al-hadist dan ljma ulama) dengan tidak melakukan kegiatan usaha yang mengandung riba.

Berdasarkan wawancara dengan Bapak Sayuti Nur adapun syarat-syarat permohonan produk gadai emas pada PT. Pegadaian (Persero) Unit Pelayanan Syari'ah Sibuhuan:

1. Membawa barang gadai yang ingin digadaikan.

2. Membawa kartu identitas atau KTP, dan seperti SIM, PASPOR, milik nasabah yang masih berlaku.

3. Mengisi formulir permintaan pinjaman (FPP) dan menandatanganinnya. 
4. Menyerahkan barang yang mau digadaikan berupa emas.

5. Menandatangani akad rahn dan ijarah.

6. Biaya admistrasi bayar diawal atau dipotong pada saat penyerahaan uang pinjamannya.

Apabila nasabah telah memenuhi syarat-syarat yang telah ditentukan PT. Pegadaian (Persero) Unit Pelayanan Syari'ah Sibuhuan maka selanjutnya pengelolah akan melakukan analisis pinjaman prosedur pemberian gadai yaitu:

a. Nasabah

1. Mengisi formulir permintaan pinjaman.

2. Menyerahkan formulir permintaan yang telah diisi lengkap dan ditandatangani dengan melampirkan KTP/Identitas lainnya serta barang yang akan dijaminkan kepada penaksir.

3. Menerima kembali duplikat formulir permintaan pinjaman sebagai tanda bukti penyerahaan dan penaksiran barang yang akan dijaminkan.

4. Menyerahkan duplikat formulir permintaan pinjaman kepada kasir.

5. Menandatanganin surat bukti gadai asli dan duplikat yang diserahkan oleh kasir.

6. Menerima sejumlah uang dan surat bukti gadai asli setelah membayar biaya admistrasi.

b. Penaksir

1. Menerima formulir pemberian pinjaman, KTP/Kartu identitas lainnya dan marhun.
2. Petugas pegadaian harus memeriksa kelengkapan dan kebenaran syaratsyarat calon nasabah pada PT. Pegadaian (Persero) Unit Pelayanan Syari'ah Sibuhuan.

3. Penaksir akan melakukan analisis terhadap data pemohon atau nasabah, keaslian dan karat jaminan berupa emas dengan menggunakan uji untuk memastikan barang yang di gadaikan nasabah bukan mas palsu.

4. Apabila menurut penaksir, pemohon layak untuk menggadaikan emasnya maka pihak pegadaian akan melakukan (qord) gadai emas.

5. Menentukan biaya admistrasi.

6. Menyerahkan duplikat formulir pemberian pinjaman yang telah ditandatangani.

7. Mengisi dan menandatangani surat bukti gadai rapkap dua sesuai kewenangan.

8. Merobek kitir bagian luar surat bukti gadai duplikat dan menyimpan bersama barang gadai.

9. Menyerahkan asli duplikat surat bukti gadai kepada kasir.

10. Menyusun surat bukti gadai duplikat, menghitung jumlah barang gadai, taksiran, kemudian menuliskan pada halaman belakang surat gadai duplikat nomor terakhir pada hari itu.

11. Mencocokkan jumlah barang gadai yang telah disusun atau diikat dan menyerahkan kepada 
penyimpan/pemegang gudang dengan menggunakan buku serah terimah barang gadai dengan memberikan tanda tangan dikolom"penyerah".

c. Kasir

1. Menerima surat bukti gadai asli dan duplikat yang telah ditandatangani penaksir.

2. Memeriksa kelengkapan dan keabsahan surat bukti gadai dari penaksir.

3. Mencocokkan duplikat formulir pemberian pinjaman dari nasabah dengan surat bukti gadai.

4. Meminta tandatangan nasabah dan melakukan pembayaran UP sebesar yang dicantumkan disurat bukti gadai.

5. Mengisi buku pinjaman berdasarkan surat bukti gadai duplikat.

6. Menyerahkan surat bukti gadai duplikat ke penaksir dan menyerahkan pemberian pinjaman.

d. Petugas Gudang

1. Memeriksa, menghitung dan menerima marhun yang diserahkan oleh penaksir.

2. Mencocokan marhun yang diterima dengan jumlah yang tertera pada buku serah terima marhun.

3. Menyimpan marhun yang diterima sesuai dengan golongan dan bulan pinjaman di gudang.

Prosedur pelunasan pinjaman pada PT. Pegadaian (Perso) Unit Pelayanan Syari'ah Sibuhuan:
POINT Vol. 2, No. 1, Jul 2021

1. Membayar pokok pinjaman di kantor PT. Pegadaian (Persero) Unit Pelayanan Syari'ah Sibuhuan.

2. Bersamaan dengan pelunasan pokok pinjaman, marhun yang telah dikuasai oleh pegadaian dikembalikan kepada nasabah dengan membayar ijarah sesuai dengan tarif yang telah ditetapkan.

3. Pelunasan pinjaman dapat juga dilakukan dengan cara melelang marhun apabila nasabah tidak memenuhi kewajibannya pada tanggal jatuh tempo. Hasil lelang tersebut digunakan untuk melunasi pinjaman daan membayar ijarah serta biayabiaya yang timbul atas lelang barang tersebut.

4. Apabila harga lelang tersebut melebihi kewajiban nasabah, maka sisanya dikembalikan kepada nasabah.

5. Apabila hasil dari lelang tersebut tidak mencukupi pokok pinjaman dan ijarah serta biaya lelang barang, maka kekurangan tetap menjadi kewajiban nasabah. Tetapi apabila ternyata nasabah tidak mampu memenuhi tambahan kewajiban tersebut, maka pelunasan pinjaman diselesaikan menurut ketentuan yang berlaku di pegadaian tersebut.(Sayuti Nur: 2020)

Risiko Produk Gadai Emas pada PT. (Persero) Unit Pelayanan Syari'ah Sibuhuan

Risiko adalah suatu peluang terjadinya kerugian atau kehancuran yang kemungkinan terjadinya hasil yang tidak diinginkan. Pegadaian syari'ah juga memiliki berbagai 
macam risiko, berdasarkan wawancara adapun jenis-jenis risiko yang dihadapi PT. Pegadaian (Persero) Unit Pelayanan Syari'ah Sibuhuan antara lain:

\section{Risiko Pasar}

Hasil penelitian wawancara risiko pasar adalah risiko yang melekat pada instrumen dan aset yang diperdagangkan di pasar, kerugian ini muncul sebagai akibat terjadinya perubahaan harga pasar. Risiko penurunan harga emas akan berakibat kerugian pada saat lelang pada PT. Pegadaian (Persero) Unit Pelayanan Syari'ah Sibuhuan, pada saat lelang harga emas turun itu tidak termasuk keperusahaan itu ditunggu sampai harga emas stabil lagi, untuk menghindari hal tersebut agar tidak terjadi kerugian bagi perusahaan.

2. Risiko Kredit

Hasil penelitian wawancara risiko kredit adalah kegagalan nasabah dalam melunasi pinjamannya pada PT. Pegadaian (Persero) Unit Pelayanan Syari'ah Sibuhuan sehingga barang jaminannya akan dilelang dan barang lelang bisa saja mengendap dalam perusahaan karena tidak setiap waktu barang lelang bisa terjual dengan cepat. Selain itu apabila barang yang digadaikan tidak laku dilelang atau terjual dengan harga yang lebih rendah dari pada nilai taksiran yang telah dilakukan pada awal pemberian pinjaman kepada nasabah yang bersangkutan maka barang yang tidak laku dilelang tersebut dibeli oleh Negara dan kerugian yang timbul ditanggung oleh perusahaan.

3. Risiko Operasional

Hasil penelitian wawancara risiko operasional adalah kerugian yang diakibatkan ketidak cukupan proses di dalam manajemen, masuknya emas palsu akan mengakibatkan kerugian bagi perusahaan. Masuknya emas palsu merupakan hal yang sangat fatal bagi perusahaan karena masuknya emas palsu merupakan kelalaian dari seorang penaksir yang tidak teliti dan kurang berhati-hati pada saat memeriksa keaslian kadar emas tersebut. Menurut hasil wawancara dari bapak Sayuti Nur jika terjadi risiko taksiran emas atau taksiran tinggi, nasabah menggadaikan emasnya hanya 16 karat tetapi petugas menaksirnya 20 karat, maka terjadi ada perselisian 4 karat itu termasuk taksiran tinggi maka disitu petugas dapat pembinaan dari spi. Jika terjadi lelang ada selisi harga yang tidak cukup untuk menutupi kewajibannya itu karena terjadi kesalahan dari si pegawai salah menaksir barang. Jika terjadi taksirannya rendah taksirannya itu 24 karat tapi si pewagai menaksir hanya 20 karat direndahkan disitu si pegawai juga dapat pembinaan dan teguraan, binaannya itu seperti untuk membuat si pewagai itu biar lebih propesional lagi dalam bekerja, kerugian seperti ini semua ditanggung si pegawai. 
4. Risiko Hukum

Hasil penelitian wawancara risiko hukum adalah risiko yang timbul akibat terjadinya kejahatan, baik pencurian maupun kecurangan pegawai. Dapat menimbulkan kerugian bagi PT. Pegadaian (Persero) Unit Pelayanan Syari'ah Sibuhuan.

5. Risiko Reputasi

Hasil penelitian wawancara risiko hukum adalah risiko yang timbul akibat terjadinya kejahatan, baik pencurian maupun kecurangan pegawai. Dapat menimbulkan kerugian bagi PT. Pegadaian (Persero) Unit Pelayanan Syari'ah Sibuhuan.

6. Risiko Bencana Alam (force majeur) Kemungkinan risiko yang terjadi karena kebaran merupakan ancaman yang paling besar, mungkin adanya ketidak sengajaan dengan bermain-main api yang menyebabkan barang jaminan emas yang digadaikan menyebabkan hangus terbakar.(Sayuti Nur: 2020)

Langkah-Langkah Meminimalisasikan Risiko Produk Gadai Emas pada PT. Pegadaian (Persero) Unit Pelayanan Syari'ah Sibuhuan

Berdasarkan hasil wawancara adapun langkah-langkah yang dilakukan oleh PT. Pegadaian (Persero) Unit Pelayanan Syari'ah Sibuhuan untuk meminimalisasikan risiko terhadap produk gadai emas antara lain:

1. Pemantauan

Pemantauan terhadap proses risiko produk gadai emas dilakukan oleh satuan pengawasan yaitu Kepala PT. Pegadaian
POINT Vol. 2, No. 1, Jul 2021 (Persero) Unit Pelayanan Syari'ah Sibuhuan yang secara priodik melakukan pemeriksaan terhadap unit kerja pegadaian pada produk gadai emas yang digadaikan oleh nasabah, sistem pengawasan ini dilakukan dalam kantor unit sendiri yang mekanisme pengawasannya dilakukan oleh Kepala PT. Pegadaian (Persero) Unit Pelayanan Syari'ah Sibuhuan.

2. Pembinaan

Melakukan perbaikan terhadap penerimaan keaslian gadai emas yang akan diterima sebagai agunan. Penaksir sangat berperan penting dengan keaslian emas yang akan digadaikan, oleh karena itu perlu adanya pembinaan khusus yaitu dengan dilaksanakan. Diklat atau semininar, refresing pegawai agar si pegawai tidak kecolongan lagi dengan adanya emas palsu, untuk mengulang kembali lagi cara-cara menaksir agar tidak masuk emas palsu lagi, apabila terdapat masuk emas palsu maka si pegawai akan cepat fotokan dokumentasinya dan disebarkan agar tidak bisa masuk lagi ke perusahaan lainnya karena sudah terlihat.

3. Perusahan Harus Lebih Cermat Melihat Harga Emas

Berdasarkan hasil wawancara taksiran emas di pegadaian selalu dibawah harga pasar 15\%. Harga emas mengalami penurunan saat terjadinya lelang, emas yang sudah dijualkan untuk menutupi pokok pinjaman, 
jasa kewajiban nasabah yang wajib untuk ditutupi.

\section{PENUTUP}

\section{Kesimpulan}

Berdasarkan hasil penelitian yang dilakukan oleh peneliti pada PT. Pegadaian (Persero) Unit Pelayanan Syari'ah Sibuhuan maka peneliti menyimpulkan:

1. Mekanisme dan prosedur pemberian pinjaman pada PT. Pegadaian (Persero) Unit Pelayanan Syari'ah Sibuhuan adalah nasabah yang ingin menggadaikan barang jaminannya mengisi formulir terlebih dahulu kemudian penaksir akan menaksir barang nasabah setelah ditaksir akan didapatkan jumalah uang dapat diterima oleh nasabah setelah ditaksir akan didapatkan jumlah uang dapat diterima oleh nasabah sesuai dengan taksiran setelah itu penaksir akan memberikan formulir kepada kasir dan penaksir akan memberikan sejumlah uang yang ingin dipinjam oleh si nasabah. Sedangkan untuk pelunasan barang gadai nasabah membawa bukti formulir atau surat bukti rahn dan sejumlah uang sebesar biaya perawatan yang sudah tertera di surat bukti rahn tersebut ke kasir dan akan diproses oleh kasir setelah itu nasabah akan mendapatkan barang jaminannya kembali.

2. Risiko yang terjadi pada PT. Pegadaian (Persero) Unit Pelayanan Syari'ah Sibuhuan adalah risiko pasar, risiko operasional, risiko kredit, bencana alam. Risiko pasar adalah risiko yang melekat pada instrument dan aset yang diperdagangkan dipasar seperti risiko penurunan harga emas yang akan berakibat menimbulkan kerugian pada saat lelang. Risiko operasional adalah risiko yang ditimbulkan oleh ketidakcukupan proses dalam memanajemen seperti masuknya emas palsu. Risiko kredit adalah kegagalan nasabah dalam melunasi pinjaman sehingga barang jaminannya akan dilelang dan barang lelang bisa saja mengendap dalam perusahaan karena tidak setiap waktu barang lelang bisa terjual dengan cepat. Bencana alam risiko yang terjadi karena kebaran merupakan ancaman yang paling besar, mungkin adanya ketidak sengajaan dengan bermain-main api yang menyebabkan barang jaminan emas yang digadaikan menyebabkan hangus terbakar.

3. Berdasarkan langkah-langkah yang dilakukan oleh PT. Pegadaian (Persero) Unit Pelayanan Syari'ah Sibuhuan dalam meminimalisasikan risiko yang terjadi pada produk gadai emas itu adalah dengan pemantauan dan diberi pembinaan serta melaksanakan diklat dan refresing pegawai agar penaksir tidak kecolongan lagi dengan masuknya emas palsu dan tidak salah penaksiran.

\section{Saran}

Semoga adanya pengetahuan masyarakat terhadap minat produk perbankan syariah 


\section{DAFTAR PUSTAKA}

Abdul Nasser Hasibuan, The Effect of Profitability Ratios on Financial Distress in Islamic Commercial Banks in Indonesia.

Ali Hardana, Analisis Faktor-Faktor Yang Mempengaruhi Pendapatan Industri Kecil Di Kota Padangsidimpuan Dan Kabupaten Tapanuli Selatan.

Adrian Sutedi. (2011). Hukum Gadai Syariah. Bandung: Alfabeta.

Ahmad Nizar. (2014). Metode Penelitian Pendidikan. Bandung: Cipta Pusta Media.

Al-Fatih. t.t. Al-Quran Dan Terjemahan (Jakarta: Insan Media Karya,). 49.

Andri Soemitra. (2017). Bank dan Lembaga Keuangan Syariah. Depok: Kencana.

Bambang Rianto Rustam. (2017). Manajemen Risiko Prinsip Penerapan dan Penelitian. Jakarta: Hak Cipta.

Darwis Harahap. (2018). "Produk Gadai Emas di Perbankan Syariah: Analisis MaslahahEkonomi."

Delima Sari Lubis. (2018). "KONTROVERSI HUKUM PEGADAIAN SYARIAH."
Herman Darmawi. (2011). Manajemen Risiko. Jakarta: Bumi Aksara.

Ikatan Bankir Indonesia. (2014). Mengenal Operasional Perbankan 2. Jakarta: Gramedia Pustaka Utama.

Irham Fahmi. (2014). Bank dan Lembaga Keuangan Lainnya Teori dan Aplikasi. Bandung: Alfabeta.

Khaerul Umam. (2013) Manajemen Perbankan Syariah. Bandung: Pustaka Setia.

Muslih, dkk. (2016). Manajemen Risiko Perusahan. Medan: Hak Cipta.

Nofinawati, Persepsi Pedagang Pasar Inpres Sadabuan Terhadap Baitul Mal Wat Tamwil (BMT) Insani Padangsidimpuan

Sayuti Nur. (2020). “PT. Pegadaian (Persero) Unit Pelayanan Syari'ah Sibuhuan."

Soisno Djojosoedarso. (2003). "Prinsip-Prinsip Manajemen Risiko Asuransi."

Syekh H. Abdul Halim Hasan. (2006). Tafsir AlAhkam. Jakarta: Kencana.

Zainuddin Ali. (2016). Hukum Gadai Syariah. Jakarta: Sinar Grafika. 